\title{
Analysis of the 'Cappadocian cave house' in Turkey as the historical aspect of the usage of nature as a basis of design
}

\author{
P. Yildiz \\ Department of Interior Architecture and Environmental Design, \\ Hacettepe University, Turkey
}

\begin{abstract}
The Cappadocia region is located in the Anatolian part of Turkey surrounded by ancient civilisations where nature and history came together in good sequence. While geographic events had formed 'Fairy Chimneys' (Peribacaları), during the historical period, the signs of old civilisations of thousands of years can be seen with carved houses and churches within these earth pillars. Traditional Cappadocian houses carved into stone show the uniqueness of the region. These houses are constructed on the feet of the mountain via rocks or cut stones. Rocks, which are the only construction materials of the region, as they are very soft after quarrying due to the structure of the region can be easily processed but after contact with air it may harden and turn into a very strong constructional material. Cappadocia is also known for its rock hewn churches, monasteries and underground cities.

The cave houses are old residences carved centuries ago. They overlook a vast area surrounded by mountains. Restoration sometimes makes it possible to clean the rock oxidised or blackened by smoke and to clear certain parts, filled with soil over the centuries. The structure was also consolidated and certain vaults were rebuilt by original stones. The restoration continues, attempting to respect the original construction. The purpose of this study is to analyse the historical aspect of design with the basis of nature among cave house formation, with the usage in today's conditions. The results of this study show the advantages and the disadvantages of the architectural space formed by cave structures while the conclusion is the criteria reached by the character of the residences based on natural formation.

Keywords: cave house, stone, fairy chimneys, underground cities, architectural rock construction.
\end{abstract}




\section{Introduction}

The purpose of this study is to understand the interaction of design with the basis of nature. According to architectural designing principles and relations, the aesthetical reflection in nature is so dynamic that all parts combining the whole is the ring to form the whole structure. A structure is sometimes poetic, sometimes dramatic but one thing is for sure that the most important thing for living things is the aim to supply the adaptation criteria in all changing and flexible surroundings, environments. Then the designing with the basis of nature concerns a great deal with the term adaptation. From an architectural perspective, living things from the very beginnings of earthly liveable conditions, always tried to adapt themselves to nature or adapt the natural meanings to themselves by a dynamic integration. One of the reflections of this happening is the need of shelter to prevent themselves from any harm and also from other living things like animals. In the most ancient times when there was no civilisation human beings used caves as shelter.

The caves are first sights of accommodation and space of ever in natural based interiors. The harmony between design and nature could be explained among these in historical aspect. Here, design indicates to form the internal living conditions concerning ecological ground. Some of these cave houses around some places in the world still survive and the usage of interiors are still going on. In my case study I would like to concentrate on the cave houses located in Turkey which are still being used today. These houses show the sustainability of the cave house formation as the long term usage of their spaces and with different functions.

\section{The Anatolian region of Turkey and the location of Capadoccia}

The city of Capadoccia is located in the Anatolian region of Turkey. The creation and formation of the Capadoccian landscapes began when 'Mount Argaeus' erupted millions of years ago, smoothening the entire surroundings with a torrent of lava that covered hundreds of kilometres.

High on the central Anatolian plain, close to the country's geographic centre, is a landscape with fairy chimneys capped with basalt to resemble giant mushroom shaped rocks. Others formations have been carved by wind, sand and rain into the shape of mythological beasts. Nearby stand cones hundreds of feet high. Volcanic eruptions $30 \mathrm{~m}$ years ago coated the land with ash, which over millennia compacted into the soft tufa rock. This the Hittites, who occupied the country in the third millennium $\mathrm{BC}$, found easy to excavate into caves for storage at a constant cool temperature. As the Anatolian Region was fought over by successive empires, the inhabitants found it political to disappear, digging out secret cities in which to survive for months at a time. By the first century AD early Christians were using them to hide from Roman persecution. Some of the Capadoccian cave villages remained in occupation until recent times. Fairy chimneys, strange cone shaped rocks, formed due to centuries of erosion. 


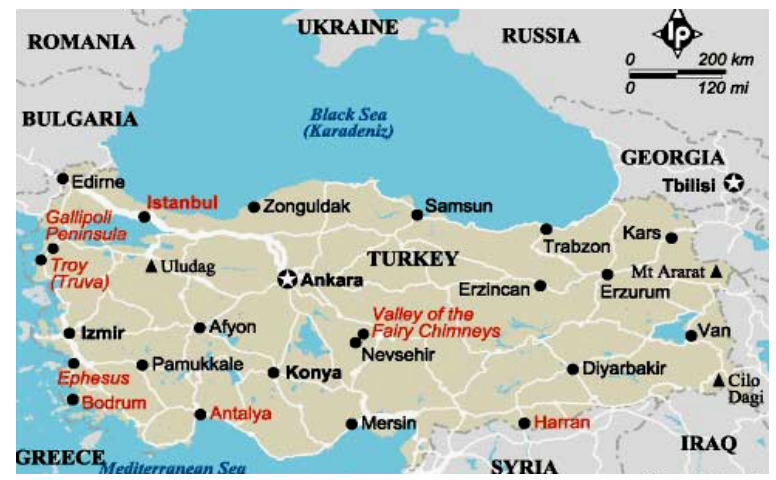

Figure 1: The geographical statement of Capadoccia in Turkey.

The most commonly held view is that the cities were excavated during Roman and Byzantine times [6]. Certainly during these years the region was often beset by internal strife in the form of persecutions of local Christian communities and external attacks by the Arabs. After the region was incorporated into the Ottoman Empire, in the 14th Century, the external threat abated, the Byzantines were forced to leave the area and with the outbreak of peace, the abandonment of the underground cities began.

\subsection{The ecological and geographical statement of Capadoccia}

It took millions of years for the ash from these volcanoes to form a layer of tuff, covered in places by a further layer of basalt lava. The basalt ultimately cracked and split under attack from the weather and rainwater seeped down through the cracks and splits to slowly erode the tuff itself.

The natural effects of alternating very hot and very cold weather and the rain and the wind breaking down the rock's resistance caused the emergence of the tall cones of tuff capped by hard basalt, which is called 'Fairy Chimneys'.

Where there is no basalt layer to protect the tuff lovely valleys have been formed connected to the plateau by steep canyons of andesite and basalt. The canyons of Soğanl 1 and Ihlara are particularly stunning examples, Ihlara canyon being 650 feet in depth in some parts.

Geographically located in the centre of the country, Capadoccia is a mountain area that was created from a series of volcanic eruptions. Capadoccia is famous for its fairy chimneys, sort of strange shaped rocks (tuff rocks) sculpted by the erosion work. Thereby this natural property allowed Capadoccia to be a member of the UNESCO World patrimony.

There are caves, cave houses, churches and also whole underground villages in this region which still survive and which are being used at present. This landscape was created many millions of years ago at the time when the two volcanic mountains covered a vast area with lava and dust. Capadoccia is known today for its underground settlements as well as its painted Byzantine cave churches [1]. Roughly 50 to 150 million years ago, repeated volcanic eruptions 
and subsequent erosion in central Turkey created a series of interconnected valleys, surrounded by limestone plateaus.

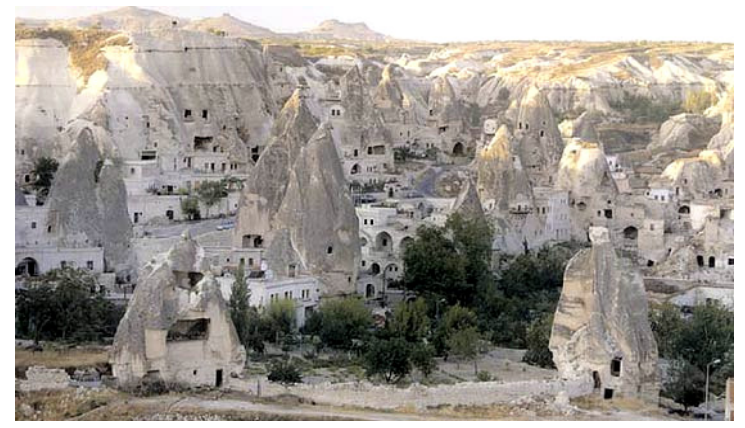

Figure 2: The sight of cave houses in Capadoccia.

The site recently surveyed under the auspices of the German Archaeological Institute, preserves the remains of hundreds of small rubble houses and several churches. The evidence for rock-cut architecture and fresco painting is more limited in the early Christian period.

The valleys are sheltered and fertile with an almost temperate climate. The tuff is easily worked and for millennia has provided dwellings and store rooms, both above and below ground, for smallholders.

This subterranean way of life resulted from several different factors. The dramatic landscape of Cappadocia is formed from tufaceous rock which is easy to work but which dries to a hard surface resistant enough to allow the excavation of wide rooms with horizontal ceilings. Trees producing wood suitable for building use are scarce in Capadoccia so even the surface dwellings are barrel vaulted using squared tufaceous stone.

Because of the nature of the land, many churches, monasteries and dwellings were cut from the rock rather than built. Typically a living unit was cut into the slope of a hill with carved chambers organized around three sides of a courtyard. The Capadoccian carvers began by burrowing out the centre of a space, perhaps following a natural fissure, next they roughed out the whole and carved the details.

This building culture, making use of existing formations rather than creating specialist building materials, can be found throughout the world but is particularly strong in the Mediterranean region. Capadoccia's underground cities are, however, unique in their range, their complexity, their variety and possibly in the time periods in which they were developed. Subsequently the dried lava were sawed away through generations of rain, wind and floods, thereby creating deep valleys, while the slopes were carved into the astonishing cones and columns we see today. Generations of local people have carved innumerable doorways and rooms in the rocks over an area of several hundred square kilometres. Some were homes for farmers, others were stables and chapels. Quite early on the inhabitants of this area discovered that the dust was very fertile and 
also that it was possible to carve this stone material. They, therefore, over generations, made carves and store rooms in these rock formations.

\subsection{The material analysis}

The terrain consists almost exclusively of a fine-grained, compressed ash, creating Capadoccia's characteristic cone formations. In some instances, a layer of nonvolcanic rock remains balanced picturesquely on an eroded cone, producing fairy chimneys. In some areas the rock has a pinkish hue from the underlying sand bed. In the less-explored area of western Capadoccia, the volcanic landscape offers equally intriguing formations [7].

\section{The sustainable meaning of cave house formation}

In the region the aspect of functionality is a sustainable matter of fact. The interiors and environments of cave houses that have been used for hundreds of years are still being used in today and they also serve the functions and needs of present life. The energy conservative property of the interiors and functions suitable to climate factor are the reasons of sustainability. Also the functions that let these hoses survive are another factor to be recognized.

There are still some semi-subterranean rooms in use. The underground storage of produce is common practice particularly around Ortahisar, where large quantities of locally grown potatoes and citrus fruits brought from the South coast are stored. The climate of Capadoccia is continental. Summers are hot and sunny but the altitude provides cool nights. At winter time, the climate is cold and the fairy chimneys are totally metamorphosed when covered with snow [10].

The underground sites are particularly useful for storage as the outdoor temperature can vary from minus $20^{\circ} \mathrm{C}$ to nearly $40^{\circ} \mathrm{C}$. The internal temperature of the sites remains constant throughout the year at $7^{\circ} \mathrm{C}$ to $15^{\circ} \mathrm{C}$ depending on the proximity of the air shafts.

\section{The underground cities found in Capadoccia region}

The underground cities were long stay settlements and they were built to withstand attack and to support long numbers of people and their domestic animals for long periods of time. More than 40 multi-storeyed underground settlements have been identified. In times of peace the people of this area could live and farm above; however, when they were being invaded by enemies they would retreat into these underground safe places where they could survive for up to 6 months. Some of these underground cities are still used today [10].

The urban organization was very complex and extensive networks of passages, tunnels, stepped pits and inclined corridors link family rooms and communal spaces where people would meet work and worship. The cities were complete with wells, chimneys for air circulation, niches for oil lamps, stores, water tanks, stables and areas where the dead could be placed until such time as conditions on the surface would allow their proper disposal. Most importantly, 
carefully balanced moving stone doors, resembling mill stones, were devised to quickly block corridors in the event of an attack [7].

One of these cities is called 'Derinkuyu'. which is a huge complex having 8 underground floors and reaching a depth of 55 meters $(180 \mathrm{ft}$.). This underground city was built in $1300 \mathrm{BC}$. The city had excellent ventilation made possible by ventilation shafts, the deepest reaching depths of 85 metres. There could be as much as 20 levels underground.

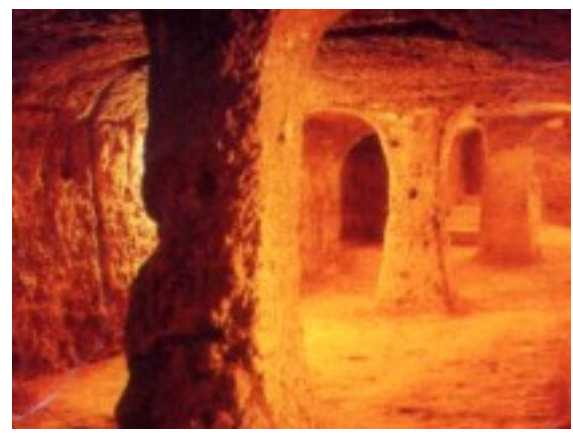

Figure 3: The underground cities in Capadoccia.

\section{The architectural formation and space planning in Capadoccia houses}

The architectural elements of the rock-cut buildings were carved in imitation of Byzantine architecture. But there is an important difference. Most architectural features in rock-cut buildings are mere adornments with no structural purpose. Interior columns, for example, do not support roofs; they exist simply as decoration [5].

With the malleable volcanic rock, work would have proceeded quickly. A room 25 feet long, 14 feet wide and 10 feet high probably took a single man about a month to complete. Theirs is primarily architecture of interiors, though the Capadoccians sometimes gave their rock-cut buildings detailed facades, with gables and horseshoe-shaped arches.

The cave room has a smallish window; it is cooler than outside. The people who used to stay in this valley lived in such caves because they kept them cool in summers and provided warm waters in winters even though temperatures would take a dive after the sun set.

In figures 4 and 5 we can see houses of stone around the Capadoccia region [2]. All these houses have similar characteristics. These characteristics are:

-Approximately all houses are formed by the basis of nature and ecological statement.

-The usage of interiors is sustainable as the air quality of the interior is suitable to the climate and the long term usage between cultures and societies is recognized. 
-The functions of the structures are residences, houses, churches and storerooms.

-The most common material is stone added with wood so as to be suitable to climate and geography.

-The practical usage and interaction with environment are also characteristics in common.

-The interior organization of spaces is non-flexible and stable.

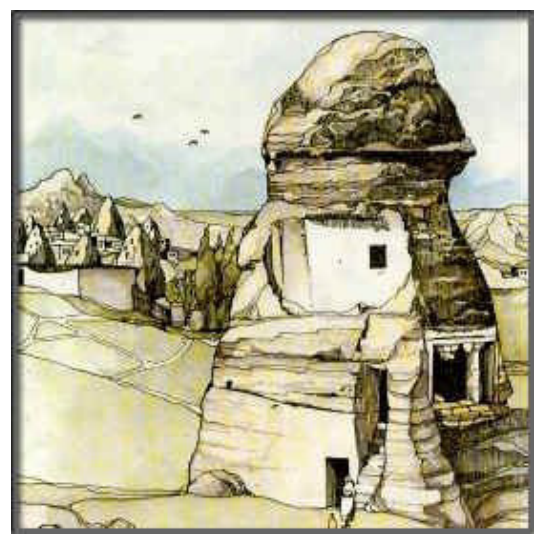

Figure 4: $\quad$ A house in Capadoccia Uchisar.

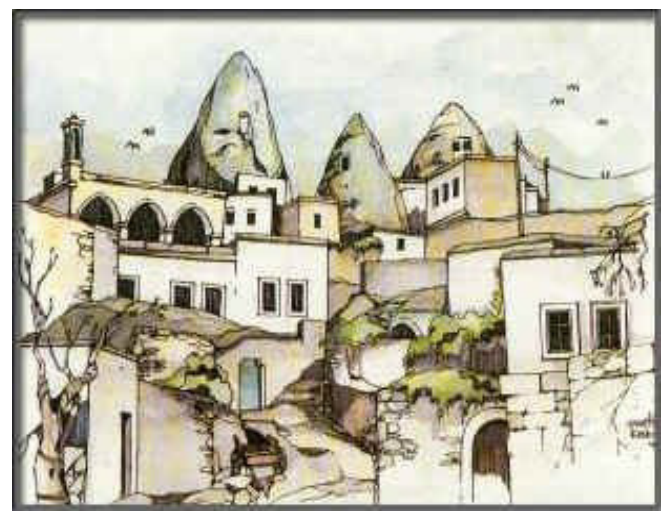

Figure 5: A house in Capadoccia Avcilar.

In figures 6 to 8 we can see the naturally based stone houses in harmony with Capadoccian ecological formation. These are not cave houses but built by sequence with the cave formation and parallel with the architectural symbol of cave. 


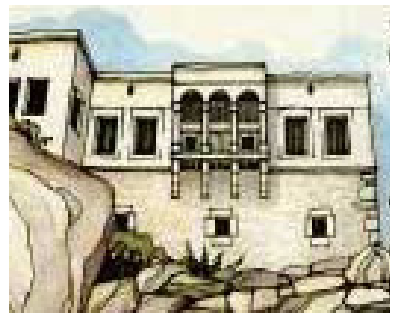

Figure 6: The typical view of a house in Güzelyurt.

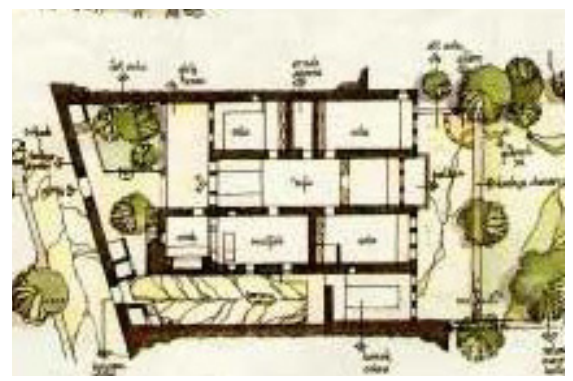

Figure 7: The plan view.

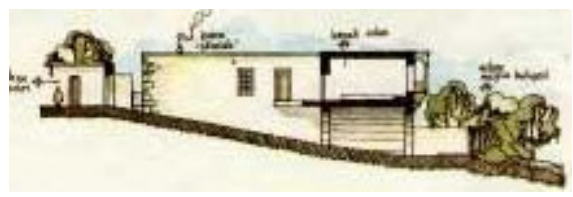

Figure 8: $\quad$ The side view.

\subsection{The analysis of atypical cave house in Capadoccia}

The cave houses that are still being used in today's conditions have functions as residences [11]. The cave house complex is the restored stone village houses, each different in architecture and character. These houses are a combination of six cave houses with a total of 17 private cave rooms dating back to $5^{\text {th }}$ and $6^{\text {th }}$ centuries and crowned with a $19^{\text {th }}$ century Greek Mansion. But several are fifth, seventh century cave houses burrowed deep into the cliff that embraces the small market town. The experience of inhabiting one is surprisingly serene and dry although erosion and reconstruction have supplied windows and doors where originally there was a blank rock face with a concealed underground entrance. Now there are bathrooms with modern plumbing and sanitation. This is because enough of the surrounding Cliffside has eroded to reveal the pattern of troglodyte house, from stables at the lowest level to living rooms above and at the highest 
level kitchens, from which smoke filtered up through the porous rock to escape invisibly from the hilltop. These exceptional cave houses are renovated and decorated with care and in their own distinct style while strictly respecting the local character. The décor is elegant and personalized with hand-crafted furnishings and antiques. There are 17 rooms in this cave. These are the balance between modern comfort and tradition [11].

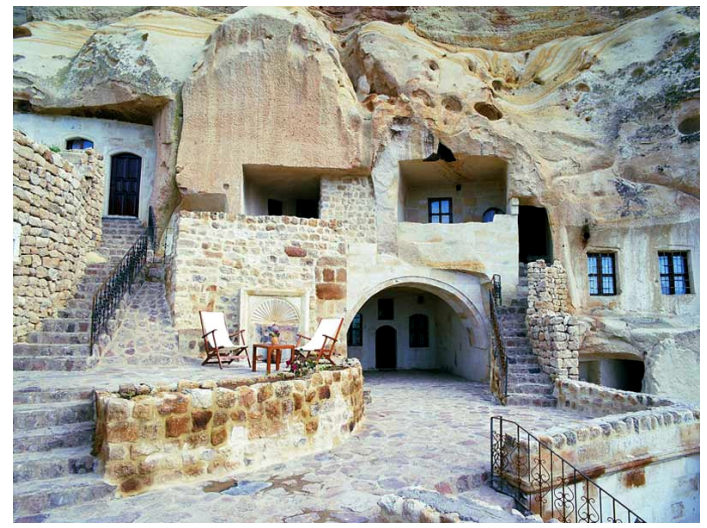

Figure 9: $\quad$ The Cave house (Yunak House) in Capadoccia.

\section{Results}

\subsection{The advantages of cave house formation}

The main advantages of interior space planning in cave houses that this study reveals are:

-The virtual and mystic atmosphere of the cave interior,

-The air quality of houses regarding the climate,

-The sustainability factor of cave house among cultural, ecological, aesthetical etc. approaches.

-The adequate formation of ecology based architecture.

-The historical feature of space with a language of many cultures and religions.

\subsection{The disadvantages of cave house formation}

Because of the limited properties of space planning of cave interiors some disadvantages can be listed as follows:

-The impossibility of the flexible interior organisation,

-The improper sizes of interior dimensions as their naturally characteristic constructions,

-The impossibility of the multidisciplinary and optimal space formation, -The lack of acoustical criteria as the usage of stone which is not proper for noise absorption and has the characteristic to reflect it. 


\section{Conclusions}

Cave houses are important archetypes of space as they indicate the cultures, religions and tradition of centuries. As they are still being used today great concern must be shown and more adequate functions should be added so as to reach a more sustainable meaning to increase the concept of the language of space survived from centuries in order to let them be useful for more and more years by great recognition.

The most important thing in this study is to understand the importance of the historical aspect of design with the basis of nature and to create contemporary solutions in today's design problems with the solutions found in these types of natural architectural spaces. These spaces should be a sample for contemporary designers to create new sustainable spaces. Knowing the historical background of design and nature with the samples in which they are in good sequences designers could reach more and more liveable interiors with contemporary means and without energy loss. These criteria should be carried at the first levels of education in design training and be adapted beginning from graduate study.

Nature is a gift to all designers as it potentially carries important values like aesthetics, energy, dynamical circulation of life, materials, daylight, air, transformation etc. As designers use the present values of nature without giving any harm and instead by energy conservation then more optimal solutions could be reached.

\section{References}

[1] Fırat, K., Kapadokya, Literatür Yayınları, Sanat Yaşam Kültür Dizisi, 1996.

[2] Küçükerman, Ö., Turkish House, Kendi Mekanının Arayışı Içinde Türk Evi, T.T.O.K Yayını, 3. Basım, 1988.

[3] Sözen, M., Anadolu Türk Mimarisi, Anadolu Uygarlıkları, Cilt 5.

[4] Ünver S. E., Amucazade Hüseyin Paşa Yalısı, T.T.O.K. Yayını, 1970.

[5] Rodley, L. Cave Monasteries of Byzantine Capadoccia, Cambridge University Press, 1986.

[6] Rodley L., Byzantine Art and Architecture. An Introduction, Cambridge University Press, 1996

[7] Capadoccia Tourism Promotion Foundation. A complete Guide to Capadoccia, ISBN 9757672106.

[8] Liew, J. Capadoccia, http://www.jehpin.com/travel/turkey/cappadocia.php

[9] http://www.turkeytravelplanner.com/photo galleries/cappadocia/

[10] http://www.wsu.edu/ wldciv/tours/turkey/cap01.html

[11] http://www.yunakevleri.com/useful_tips.html 